Supporting Information for

\title{
Acid-Catalyzed Oxidation of Iodide Ions by Superoxometal Complexes of Rhodium and Chromium
}

\author{
Andreja Bakac*, Chunkai Shi, and Oleg Pestovsky
}




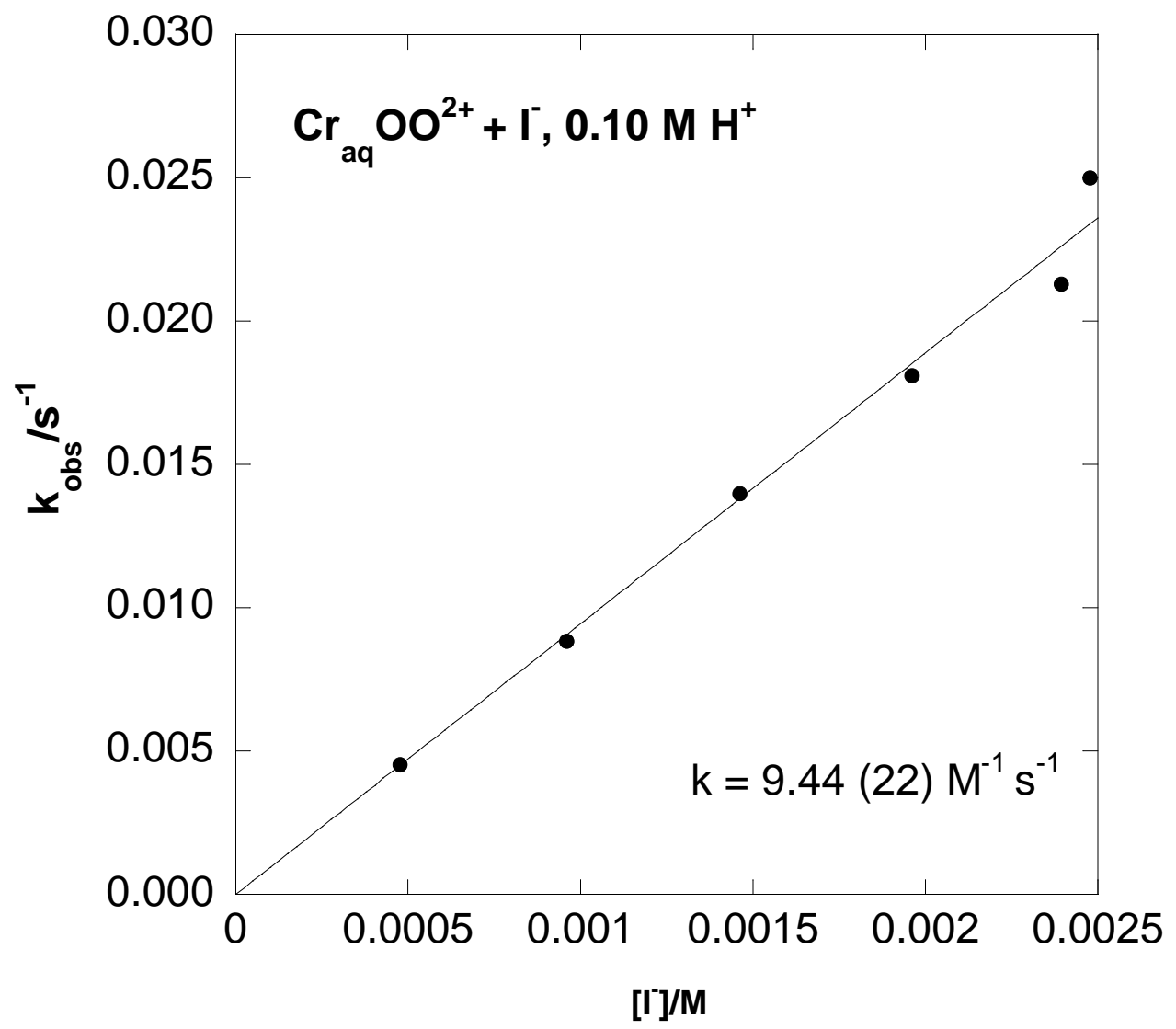

Figure S1. Plot of $\mathrm{k}_{\mathrm{obs}} v s\left[\mathrm{I}^{-}\right]$for the reaction of $\mathrm{Cr}_{\mathrm{aq}} \mathrm{OO}^{2+}(0.015-0.0 .070 \mathrm{mM})$ with iodide ions in $0.10 \mathrm{M} \mathrm{HClO}_{4}$. 


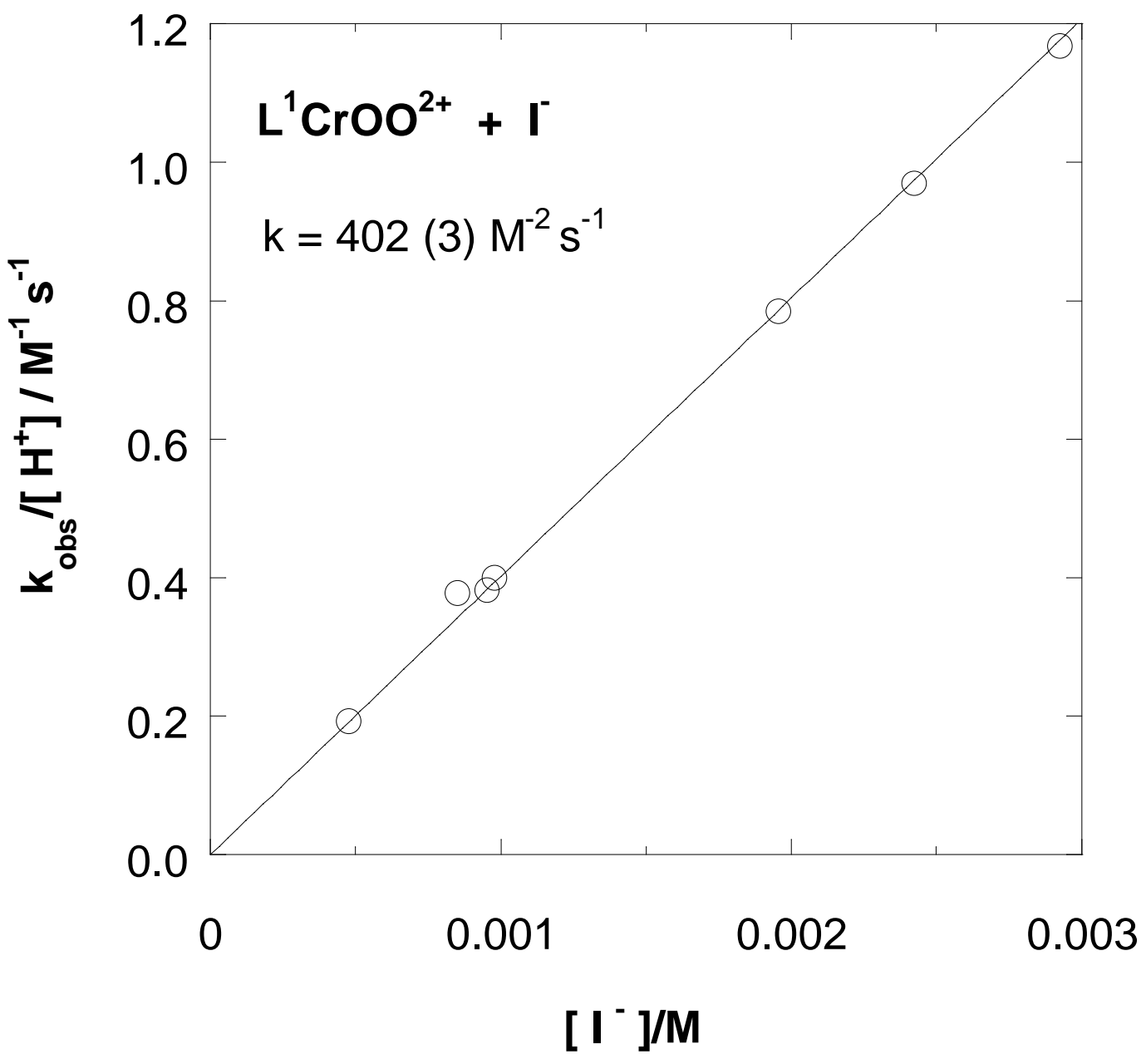

Figure S2. Plot of $\mathrm{k}_{\mathrm{obs}} /\left[\mathrm{H}^{+}\right]$vs $\left[\mathrm{I}^{-}\right]$for the reaction of $\mathrm{L}^{1} \mathrm{CrOO}^{2+}(0.015-0.10 \mathrm{mM})$ with iodide ions in $0.10 \mathrm{M} \mathrm{HClO}_{4}$. 


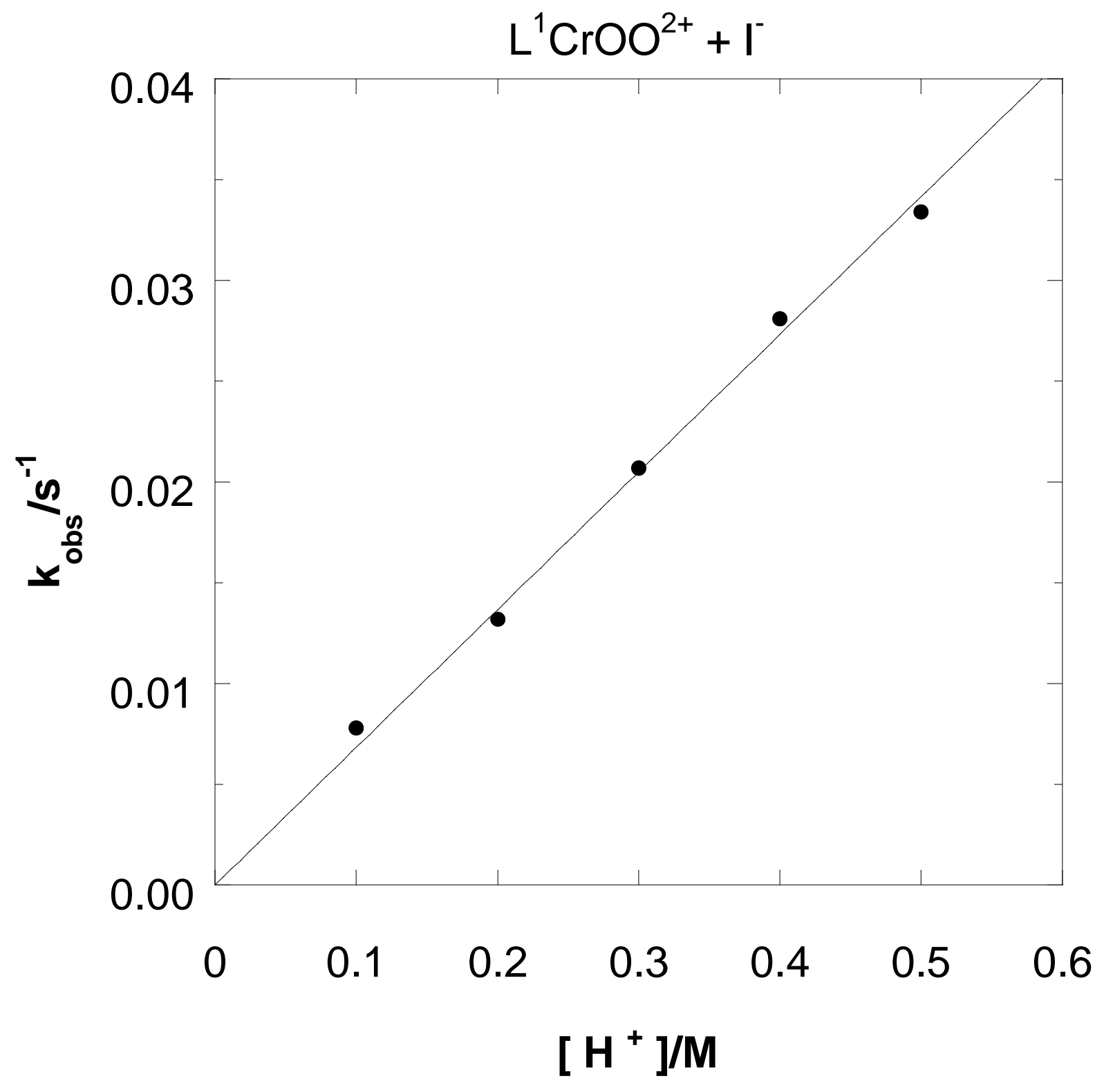

Figure S3. Plot of $\mathrm{k}_{\mathrm{obs}} v s\left[\mathrm{H}^{+}\right]$for the reaction of $\mathrm{L}^{1} \mathrm{CrOO}^{2+}(0.015 \mathrm{mM})$ with $\mathrm{I}^{-}(0.178 \mathrm{mM})$ at $0.50 \mathrm{M}$ ionic strength. 


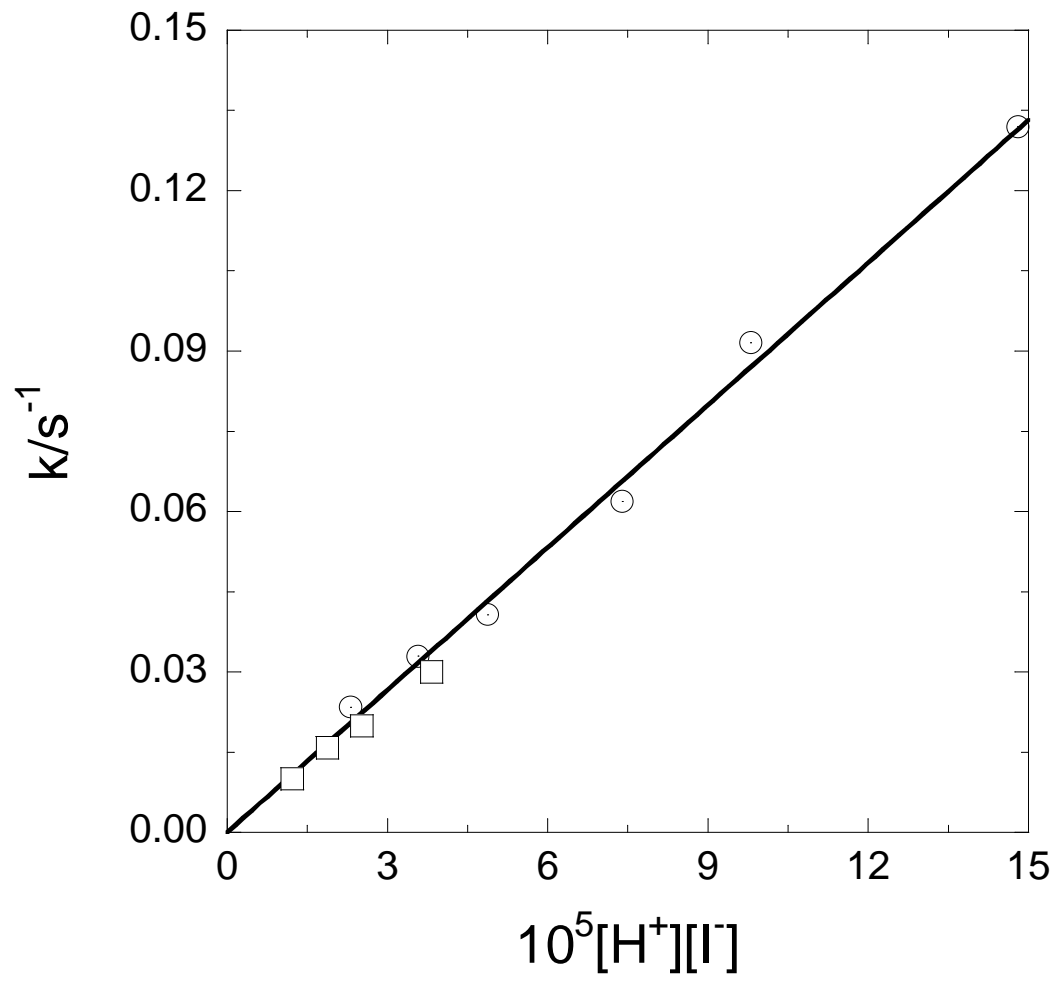

Figure S4. Plot of $\mathrm{k}_{\text {obs }} v s\left[\mathrm{H}^{+}\right] \times\left[\mathrm{I}^{-}\right]$for the reaction of $\left(\mathrm{NH}_{3}\right)_{4}\left(\mathrm{H}_{2} \mathrm{O}\right) \mathrm{RhOOH}^{2+}$ and $\left(\mathrm{NH}_{3}\right)_{4}\left(\mathrm{H}_{2} \mathrm{O}\right) \mathrm{RhOO}^{2+}$ with iodide ions at $\left[\mathrm{H}^{+}\right]=0.013 \mathrm{M}$ (squares) and $0.050 \mathrm{M}$ (circles). 